\title{
Elements Related to Teaching Pilots Aeronautical Decision Making
}

\author{
Ronda E. Cassens, John P. Young, and James P. Greenan
}

Purdue University

James M. Brown

University of Minnesota

\begin{abstract}
The Federal Aviation Administration (FAA) has placed increasing emphasis on aeronautical decision making (ADM) instruction, and it is critical that flight training schools ensure that their students are meeting and exceeding these requirements, especially since it has been shown that training in ADM can reduce the amount of errors caused by poor decision making (Berlin et al., 1982; Buch \& Diehl, 1984; Buch, Lawton, \& Livack, 1987; Connolly \& Blackwell, 1989; Telfer, 1989). The goal of this study was to determine the status of ADM training at a collegiate flight training school and if there was any need for program improvement. Two surveys were used to define the ADM training environment. One survey was designed to determine the methods that professors believe should be used to teach ADM and the elements of ADM that should be included in instruction. A second survey focused on identifying methods and elements that were currently being used by flight instructors. The results of the surveys were then compared to determine if there were significant differences between what professors of aviation believed should be taught and what flight instructors were actually teaching in regards to ADM. The findings suggest that instructors were not consistently using the types of situations that allow students to practice decision making, nor were they consistently emphasizing the different types of elements that contribute to good decision making. Recommendations based on this research included: (a) analyzing the nature of ADM-related instruction at other collegiate flight training schools using similar methodology, (b) providing additional ADM-related ground and flight instruction, (c) determining the students' perceptions of ADM instruction in the aircraft, and (d) adapting lesson plans to provide additional/more effective opportunities for students to practice ADM.
\end{abstract}

\section{INTRODUCTION}

\section{Elements Related to Teaching Pilots Aeronautical Decision Making}

Decision-related errors account for $71 \%$ of fatal accidents caused by the pilot (Aircraft Owners and Pilots Association, 2009). The Federal Aviation Administration (FAA) has begun to place more emphasis on decision making in order to help reduce the occurrence of these accidents. Its most recent program focuses on technically advanced aircraft (TAA) and is called the FAA Industry Training Standards, or FITS. This program uses scenario-based training (SBT) that goes beyond training a pilot to pass the practical test to enhance a pilot's aeronautical decision making, risk management, and single-pilot resource management skills (FAA, 2009). With this greater emphasis on ADM, it is important to ensure that students in flight training programs are receiving the skills they need to become better decision makers through continuous program evaluation and revision. Therefore, the survey that was created for this study focused on two areas, methods of ADM instruction and elements that may be incorporated in instruction.

\section{Review of the Literature}

Jensen and Benel (1977) completed the first comprehensive study of general aviation pilot judgment 
for the FAA. They found that the majority of general aviation accidents were caused by judgment errors and suggested that training programs should be developed to teach pilots good judgment, instead of simply relying on experience. Several suggestions were also made for developing programs. The recommendations that were developed from this study were revolutionary; previously, traditional flight instruction had focused on flying skills and aeronautical knowledge rather than judgment training (Jensen, 1995). Subsequent research determined that training in judgment and decision making effectively reduces the number of judgment errors that pilots make (Berlin et al., 1982; Buch \& Diehl, 1984; Buch, Lawton, \& Livack, 1987; Connolly \& Blackwell, 1989; Telfer, 1989). In short, good decision making can be taught and ADM instruction is effective. Unfortunately, many flight training programs are still utilizing traditional instructional methods, which leave little opportunity for the student to practice ADM skills.

\section{ADM Instructional Methods}

The best way to teach ADM is to introduce the basic concepts of decision making, place the student in situations where he or she can practice ADM, and positively reinforce safe judgment and decision making behaviors (FAA, 1991). There are two tools that pilots need to develop through practice to help build their ADM skills: cognitive strategies and problem solving tactics (FAA, 2008). Cognitive strategies focus on the "how" instead of knowing facts. As experience is gained, a pilot will develop strategies to deal with commonly encountered problems, providing a basis for making decisions. Problem solving tactics involve noticing a frequent type of error, and then developing methods to reduce that error. If a student makes an error during instruction, the instructor should ask the student to evaluate why the error occurred and to suggest ways to prevent it from happening again. The student should also actively identify errors, be aware of situations where an error is most likely to occur, and use standard routines and checklists to catch errors before they happen (FAA, 2008).

Another training method that emphasizes allowing a student to practice his or her judgment skills was presented by Brecke (1981). He defined judgment as "making more or less educated guesses if one does not know everything one should know in a given situation” (p. 147). As such, each training flight should include varying levels of uncertainty, as well as elements of cognitive complexity, time constraints, and stress. Judgment is more difficult to perform when there is less information, which introduces an element of uncertainty. Tasks that are more cognitively complex include several possible options. It is also more difficult to exercise judgment when there is less time to perform a task. Lastly, stress can be introduced by establishing a conflict between a flight problem and a background problem. The background problem involves things that are unrelated to the flight that can affect the outcome, such as the need to get to an important business meeting. It is essential that students distinguish between the two in order to consistently exercise good judgment. Stress can also be caused by the flight problem itself (Brecke, 1981).

Machado (2009) offered a very simple way of teaching ADM: observation. Students are usually not aware of all the decisions that an instructor is making throughout a flight; therefore, it is important for instructors to verbally share their thought processes with students. The student can then perceive how a

pilot with experience makes decisions and emulate the process. Additional suggestions for reducing the number of general aviation accidents were presented by the Joint Safety Analysis Team (2002). After examining 30 accidents they identified the decisional errors that contributed to each occurrence, and then an expert panel produced a list of recommended interventions. Some of these interventions included training to recognize in-flight hazards and their countermeasures, use of decision points to assess and revise the flight if necessary, retaining multiple options in case the flight does not proceed as planned, use of checklists, periodic assessment of the flight status (e.g., fuel, weather, fatigue, stress), use of other pilots' experiences to learn about good and bad decisions, and using the Personal Minimums Checklist developed by the FAA ( n.d.). 
Nine methods to improve ADM instruction were derived based on the suggestions presented by previous research and variety of initiatives (Brecke 1981; FAA, 2008; Joint Safety Analysis Team, 2002; Machado, 2009). They include:

1. Specifically evaluating students for their ability to exercise good Aeronautical Decision Making.

2. Allowing students to make go/no go decisions for every flight and evaluate those decisions.

3. Placing students in situations that encourage them to use good Aeronautical Decision Making procedures.

4. Introducing complex problems with time constraints and stress during flight training.

5. After a lesson, reviewing the poor decisions that were made during the flight and ways to correct them with students.

6. Encouraging students to look for judgment errors during flight.

7. Explaining decision making process during flight so students can learn by example.

8. Setting a good example of Aeronautical Decision Making for students.

9. Incorporating realistic scenarios into lessons to develop decision making skills (Cassens, 2010).

\section{Models of ADM and their Elements}

Over time, many different methods and models have been developed to teach ADM. Two different categories of models were examined in this research: classical and naturalistic. Classical models are characterized by linear, step-by-step decision making. Naturalistic models are non-linear and are modeled after how experts make decisions. The literature review covered nine various decision making models: conventional (FAA, 1991), FAA (FAA, 2008), Jensen's judgment (Jensen, 1995), drawing a box (Wright, n.d.), setting decision points (Belanger, 2001), AOPA (Peterson, 2006), SA and CoA (Orasanu \& Fischer, 1997), ADM expertise (Kochan, Jensen, Chubb, \& Hunter, 1997), and cognitive SOARing (Adams, 1994). The first six models fit into classical decision making, while the last three models use naturalistic theories.

The conventional model (FAA, 1991) is the most basic, and consists of the pilot noticing that a change has occurred that requires a decision to obtain the desired result. Then the possible responses are evaluated, and a best course of action is selected. If the change goes undetected and if the pilot's mental skills or piloting skills are lacking, an accident can result. The FAA has expanded on this simple model for use in aviation, and the following is a summary of the documents the FAA has produced in the past years.

The FAA (1991) published Advisory Circular 60-22, which listed the following steps for good decision making:

1. Identifying hazardous attitudes that can affect the safety of the flight

2. Learning how to modify behavior

3. Learning stress recognition and coping techniques

4. Developing risk assessment skills

5. Using all available resources in a multi-crew environment

6. Evaluating the effectiveness of one's ADM skills

Steps one and two involve recognizing the hazardous attitudes (antiauthority, impulsivity, invulnerability, macho, and resignation), and using their antidotes (follow the rules, think first, it could happen to me, it's foolish to take chances, and I can make a difference) to avoid having an accident. It is also important to recognize the negative impact of stress on decision making since great amounts of stress 
can decrease performance (Diehl, Hwoschinsky, Livack, \& Lawton, 1987; FAA, 1991). Risk management involves evaluating four risk areas, the pilot, the aircraft, the environment, and external pressures (PAVE). The next step is to use all of the available resources in a crew environment; however, a person who operates as a single pilot also has resources available. In single-pilot resource management (SRM), the pilot must manage resources both inside and outside the aircraft to gather and analyze information, and make decisions based on that information. Lastly, evaluating the effectiveness of one's decision making skills involves continuously monitoring the situation to ensure that the desired outcome is being achieved. One process that can be used for this purpose is the DECIDE model: (a) Detect that a change has occurred, (b) Estimate the need to react to the change, (c) Choose a desired outcome, (d) Identify actions that can control the change, (e) Do the action that will affect the change, and (f) Evaluate the effect of the action (Diehl, et al., 1987; Federal Aviation Administration, 1991, 2003).

Jensen's judgment model (1995) defined several basic abilities needed for decision making: observation, perception, curiosity, information processing, knowledge, problem solving, creativity, computation, mental fortitude, discipline, leadership, and people skills. These basic abilities are crucial to his judgment model, which includes eight steps: problem vigil, recognition, diagnosis, alternative identification, risk assessment, background factor, decision making, and action. Problem vigil involves actively searching for changes in the flight environment. Then the pilot must be able to recognize that a change could endanger the flight and diagnose the nature of the problem. Next, the pilot examines all the alternatives that would solve the problem based on knowledge of the aircraft, environment, and aviation system. These alternatives are then evaluated for their associated risks. The background factor consists of the outside influences that add bias to the entire decision making process, but has the most impact immediately before the decision is made. These influences affect the pilot's ability to make a rational decision and can include the need to arrive at the destination, pressure from the passengers, and pride. The final steps include choosing an alternative and carrying out the action.

The drawing a box model consists of breaking a large task into smaller pieces and presenting them in a logical manner that is useful for the student. Wright (n.d.) suggested a three step process:

1. Know and operate within one's capabilities.

2. Examine a given situation, evaluate current skills, and set boundaries for that situation. In other words, create a box of operating parameters.

3. Always operate within the box.

These steps must be completed before the flight begins since being in a critical situation could cause the pilot to make a rash decision. Each pilot's box will be different and will change with experience. It is also suggested that instead of thinking of ADM as Aeronautical Decision Making, it should be thought of as "Applied Decision Making." This new meaning would help encourage instructors to give students the opportunity to practice decision making during training to apply what they have learned.

The setting decision points model is based on the fact that pilot-caused accidents stem from a poor decision that was made at some point (Belanger, 2001). There are five areas discussed: hazardous attitudes, random risks, amount and type of information available, setting, and decision points. Belanger expanded on the FAA's hazardous attitudes concept by pairing the five traits with their opposites, which can be just as dangerous. Macho is paired with delicate, anti-authority is paired with unquestioning, invulnerability is paired with fearful, and resignation and impulsiveness are paired together. It is essential to operate in the middle of each spectrum. It is also important to understand the effects of random risk. Repeatedly doing something dangerous and not experiencing consequences does not make that activity safer, and each time a risk is taken, the chance of failure increases. A pilot must gather as much information as feasible to make a good decision, but not so much that he or she becomes overwhelmed. The setting in which a decision takes place can also cause a pilot to make a poor decision. Pilots should 
also make a conscious effort to make decisions, and Belanger identified several decision points, including: before going to the airport, before takeoff, enroute, and before landing.

The AOPA Air Safety Foundation (Peterson, 2006) offered a more practical method of decision making, where ADM is “doing the right thing, at the right time" (p. 1). The AOPA method describes the process used before, during, and after a flight to ensure that good decisions are made. Before the flight, the pilot should conduct a very thorough examination of all available information while still on the ground. During the flight, the pilot should enter a continuous decision making cycle, where information that the pilot already possesses (prior knowledge and knowledge gained during the preflight) is combined with the information gained during flight. The decision making process consists of three steps: anticipate, recognize, and act. After the flight is completed, the pilot should evaluate the decisions made during the flight. Things that went well and went poorly should be examined to determine if any improvements can be made, such as noticing problems sooner or taking a different action. The pilot is then better able to handle similar situations if they should occur again.

The previous models were all examples of classical decision making. The following models reflect a more naturalistic approach to decision making. Naturalistic decision making examines situations that have ill-structured problems; incomplete, ambiguous, or changing information; ill-defined, shifting, or competing goals; decisions that occur in multiple event-feedback loops; limited time available; high stakes; multiple players in the decision making process; and the need to balance personal choice with organizational norms and goals (Orasanu \& Connolly, 1993). Decision making in the aviation environment often reflects these characteristics.

The situation assessment and course of action model developed by Orasanu and Fischer (1997) was based on naturalistic decision making concepts and consisted of two main phases: situation assessment (SA) and selecting a course of action (CoA). Situation assessment involves problem definition, risk assessment of the problem, and time available to solve the problem. The next step is to choose a course of action from the available options. There are three option structures available to the pilot: rule-based, choice, and creative. A rule-based option has only one response to the particular situation that should be readily recognized by someone with expertise in the situation. A choice decision has multiple options that are based on prevailing goals and constraints. In situations where there are no suitable options available, the pilot must create his or her own options.

To help pilots become experts and exercise good judgment, they must be able to think like an expert, which is the foundation of the $A D M$ expertise model. Instead of focusing on changing the attitudes of pilots, Kochan, Jensen, Chubb, and Hunter (1997) concentrated on discovering how expert pilots think. They believed that previous approaches to ADM training had reached their maximum effectiveness due to the fact that errors in judgment are still the major cause of aviation accidents. A new cognitive model was developed to aid in training pilots to become expert pilots. The components of the model included experience (number of hours, variety, meaningfulness, relevance, and recency), risk management, problem solving, and attentional control (awareness of one's surroundings and the ability to ignore nonflight related issues).

The final model that addressed the way expert pilots think is Cognitive SOARing (Adams, 1994), which stands for Sensing, Organizing, Analyzing, and Responding to a situation. Cognitive SOARing focuses on preparation and execution, and the first preparation step in decision making is sensing changes in the environment. The next step in this process is organizing, which involves sorting, prioritizing, and structuring the information that is being sensed. The most important information is identified and used to develop an understanding of the situation or problem. Analyzing refers to the processing and evaluation of the information. The effectiveness of the pilot relies on the type of knowledge that is stored and his or her ability to retrieve that knowledge. Experts can intuitively respond to patterns without having to 
disassemble them into components. Lastly, responding consists of taking an action to change or control the situation and evaluating its effectiveness using conceptual and procedural knowledge (Adams, 1994).

The main elements of each model were compiled into a list of 22 diverse aspects with definitions and descriptions in literature by Bowman (1993) and Abner (2006):

1. change recognition

2. attitude management

3. headwork

4. course of action development

5. course of action analysis

6. course of action selection

7. risk management

8. situational awareness

9. skills and procedures

10. aviation experience

11. stress management

12. situation assessment

13. attention control

14. values

15. computing time available

16. communication

17. leadership

18. organizational influence

19. social influence

20. personality

21. dynamic problem solving

22. the poor judgment chain

\section{Purpose of the Study}

The most recent analysis of progress toward implementing ADM instruction in the collegiate flight training environment was conducted by Bowman (1993). His study focused on determining the extent to which postsecondary flight training institutions had implemented training in ADM and judgment into their curricula. This was accomplished using survey instruments. He found that $32.8 \%$ of the respondent institutions did not teach at least one of the pilot judgment and decision making curricular topics, $47.5 \%$ of the respondent institutions did not use a textbook that included pilot judgment and decision making in its content, and $29.5 \%$ of the CFI respondents had received formal training in ADM. Since it has been some time since Bowman's research, and due to the FAA's increasing emphasis on ADM training, the purpose of this research was to obtain a single point in time description of ADM instruction at a Midwestern flight training university by identifying the essential elements of ADM flight instruction and the extent to which they were being taught in that collegiate flight program. This research also sought to compare and contrast how ADM should be taught and how it was actually being taught in the targeted collegiate flight program. It was limited to one-on-one instruction in the aircraft. The study did not evaluate classroom instruction, curriculum, textbooks, or classroom materials. The research questions that were posited for this research included:

1. Which elements of ADM are important in flight instruction?

2. Which elements of ADM are being taught in flight instruction?

3. Is there is a difference between the ADM elements that should be taught and the ADM elements 
that are being taught?

4. Which instructional methods should be used to teach ADM?

5. Which instructional methods are being used to teach ADM?

6. Is there a difference between the instructional methods that should be used to teach ADM and the instructional methods that are being used to teach ADM?

Surveys of aviation professors (experts) were used to identify key components of the educational environment that should exist and surveys of flight instructors focused on how flight training is delivered at the targeted flight training institution. The surveys also revealed areas that may require program improvement.

\section{METHOD}

\section{Participants}

The population for this study was the faculty, specifically professors, associate professors, assistant professors, clinical professors, and senior aviation continuing lecturers in a collegiate flight training school. Because of the small number of available participants, all 13 of the certified flight instructors (CFIs) and aviation flight faculty who were employed by the university received surveys. Seven of the 13 faculty completed the survey. All faculty members were experts in the field of aviation flight with between 5000-10,000 hours of flight time, including four who were FAA Designated Pilot Examiners (DPEs). The faculty sample served as a panel of experts in the decision making skills that are needed to be successful in aviation. They determined the essential elements of ADM and how they should be taught. Of the seven professor respondents, one (14\%) was female. Five (71\%) of the respondents were professors at the university, and the remaining two (29\%) held full-time flight instructor positions at the university. All had a CFI license with a multi-engine instructor rating, and five were licensed ground instructors. Table 1 presents the age, total flight time, and flight instruction given for the professor sample. The subjects in the sample had a considerable amount of combined experience.

Table 1. Demographic Information for the Professor Sample

\begin{tabular}{ll}
\hline Category & N (\%) \\
\hline Age & $1(14 \%)$ \\
$18-25$ & $0(0 \%)$ \\
$26-34$ & $2(29 \%)$ \\
$35-54$ & $4(57 \%)$ \\
$55-64$ & \\
Total Flight Time (hours) & $1(14 \%)$ \\
$501-1000$ & $0(0 \%)$ \\
$1001-5000$ & $3(43 \%)$ \\
$5001-10,000$ & $3(43 \%)$ \\
$10,000+$ & $1(14 \%)$ \\
Hours of Dual Instruction Given & $2(29 \%)$ \\
$501-1000$ & $3(43 \%)$ \\
$1001-5000$ & $1(14 \%)$ \\
$5001-10,000$ & \\
$10,000+$ &
\end{tabular}

The instructor population included collegiate certified flight instructors (CFIs), which was comprised of junior aviation continuing lecturers and part-time instructors who were currently delivering flight 
instruction. The part-time CFIs were college students generally between the ages of 18 and 22. They typically had very little flight experience and flight instruction given. The junior aviation continuing lecturer CFIs were similar to the part-time instructors, with slightly more experience and some advanced instructor ratings. Three of the respondents (13\%) were female. There were 19 (83\%) instructors who were part-time instructors, and four (17\%) were junior aviation continuing lecturers. Of the 23 CFIs, seven (30\%) had obtained their instrument instructor's rating, three (13\%) had their multi-engine instructor rating, and three (13\%) had their ground instructor's license. The age, total flight time, and instruction given for the instructor sample are presented in Table 2. The instructor sample generally had significantly less total flight experience and had given fewer hours of dual instruction than the professor sample.

Table 2. Demographic Information for the Instructor Sample

\begin{tabular}{ll}
\hline Category & N (\%) \\
\hline Age & $22(96 \%)$ \\
$18-25$ & $1(4 \%)$ \\
$26-34$ & \\
Total Flight Time (hours) & $19(83 \%)$ \\
$201-500$ & $0(0 \%)$ \\
$501-1000$ & $4(17 \%)$ \\
$1001-5000$ & \\
Hours of Dual Instruction Given & $19(83 \%)$ \\
$0-200$ & $0(0 \%)$ \\
$201-500$ & $3(13 \%)$ \\
$501-1000$ & $1(4 \%)$ \\
$1001-5000$ &
\end{tabular}

\section{Research Design}

According to Gall, Gall, and Borg (2007), “descriptive research is a type of quantitative research that involves making careful descriptions of educational phenomena” (p. 300). This study obtained a single point in time description of what should be occurring in ADM training and what is actually occurring. Without an accurate description of the current status of the flight training program, program improvements cannot be identified. This study collected and analyzed data that were primarily quantitative through the use of two surveys: one for the expert faculty group and one for the flight instructor group. The surveys were nearly identical except for a few changes in the wording of the instructions to reflect what should be taught for the faculty survey and what is actually being taught for the flight instructor survey. The surveys were comprised of sections from two previously developed surveys. The first survey, created by Abner (2006), was designed to determine the essential elements of ADM in postsecondary training environments. He reviewed various ADM models and found 21 different elements that were present in these models. The second survey was developed by Bowman (1993) to ascertain whether or not ADM training had been implemented in collegiate aviation flight training programs. Portions of these two surveys were used to create the surveys that were used in this study, along with basic demographic information. A section concerning ADM instructional methods was created based on those found in the literature review.

\section{Instrumentation}

Of the 13 faculty members who received the professor survey, seven completed it, for a response rate 
of 54\%. The instructor survey was sent to 53 instructors, of which 30 instructors began the survey, for a response rate of $57 \%$. Cronbach's coefficient alpha was calculated for each scale and the total instrument to determine the internal reliability. Coefficient alpha for Part I included all the respondents. Part II of the instructor survey was calculated using only the data provided by the 23 respondents who completed the entire section. The reliability coefficients are presented in Table 3.

Table 3. Reliability Coefficients for the Professor and Instructor Survey Instruments

\begin{tabular}{lccc}
\hline Measure & $\begin{array}{c}\text { No. of } \\
\text { Items }\end{array}$ & $\begin{array}{c}\text { No. of } \\
\text { Respondents }\end{array}$ & $\begin{array}{c}\text { Cronbach's } \\
\text { Alpha }\end{array}$ \\
\hline Professor Survey & 31 & 7 & .88 \\
Part I: ADM Instructional Methods & 9 & 7 & .44 \\
Part II: ADM Elements & 22 & 7 & .86 \\
Instructor Survey & 31 & 23 & .91 \\
Part I: ADM Instructional Methods & 9 & 30 & .80 \\
Part II: ADM Elements & 22 & 23 & .87 \\
\hline
\end{tabular}

According to Nunnally and Bernstein (1994), an alpha between .70 and .80 is adequate for newly developed instruments and basic research. The Cronbach's coefficient alphas for all of the scales were .80 or higher except for Part I of the professor survey. It was very low, most likely because there was a small number of respondents and instrument items (Nunnally \& Bernstein, 1994). The total instrument and individual scales were considered to possess an adequate degree of internal consistency reliability, indicating that it would be a useful instrument for use in evaluating other flight training programs.

\section{Data Analysis}

Two identical surveys were created by the researchers based on the review of literature. These surveys included 22 elements from nine different decision making models and nine ADM instructional methods. All elements and instructional methods included a detailed definition of the item as well as an example, if necessary (Cassens, 2010). The surveys used a standard Likert-type scale: 1 = Strongly Disagree, $2=$ Disagree, 3 = Neutral, $4=$ Agree, and $5=$ Strongly Agree. Means, standard deviations, and variances were calculated for each of the professor and instructor responses. The means were used to calculate a two-tailed p-value through an unpaired t-test, which was then used to determine if there was a significant difference $(p<.05)$ between the instructor responses and the professor responses. The open-ended questions were analyzed using cross case analysis.

\section{RESULTS}

\section{Research Question 1: Which elements of ADM are important in flight instruction?}

The results from Part II of the professor survey indicated that the faculty deemed all elements to be important to ADM instruction (see Table 4). The faculty members were unanimous with respect to the flight instructor's role in emphasizing risk management during flight training. Risk management involves correctly and analytically assessing risk as opposed to assuming risk based on previous successful situational experiences (Abner, 2006; Bowman, 1993). Once areas of high risk are identified, the pilot can take the steps to reduce risk and ensure the safety of the flight. Ignoring the risks involved could lead to an accident (FAA, 2008); therefore, it was viewed as very important by the faculty. The means of the other elements ranged from 4.00 to 4.86; accordingly, virtually all elements were deemed as ones that flight instructors should be including in flight instruction. 
Table 4. Professor Ranking of ADM Elements to Incorporate into Flight Training

\begin{tabular}{lccc}
\hline Element & $\mathrm{M}$ & $\mathrm{SD}$ & Variance \\
\hline 1. Risk management & 5.00 & 0.00 & 0.00 \\
2. Course of action analysis & 4.86 & 0.38 & .14 \\
3. Course of action selection & 4.86 & 0.38 & .14 \\
4. Situational awareness & 4.86 & 0.38 & .14 \\
5. Situation assessment & 4.86 & 0.38 & .14 \\
6. Change recognition & 4.71 & 0.49 & .24 \\
7. Headwork & 4.71 & 0.49 & .24 \\
8. Course of action development & 4.71 & 0.49 & .24 \\
9. Attitude management & 4.57 & 0.53 & .29 \\
10. Skills and procedures & 4.57 & 0.53 & .29 \\
11. Stress management & 4.57 & 0.53 & .29 \\
12. Communication & 4.57 & 0.53 & .29 \\
13. Poor judgment chain & 4.57 & 0.53 & .29 \\
14. Attention control & 4.43 & 0.53 & .29 \\
15. Leadership & 4.43 & 0.53 & .29 \\
16. Organizational influence & 4.43 & 0.79 & .62 \\
17. Social influence & 4.43 & 0.79 & .62 \\
18. Dynamic problem solving & 4.43 & 0.53 & .29 \\
19. Computing time available & 4.29 & 0.49 & .24 \\
20. Aviation experience & 4.14 & 0.38 & .14 \\
21. Values & 4.00 & 0.58 & .33 \\
22. Personality & 4.00 & 1.00 & 1.00 \\
\hline
\end{tabular}

\section{Research Question 2: Which elements of ADM are being taught in flight instruction?}

In Table 5, the elements that are actually being taught by the flight instructors were determined through Part II of the instructor survey and then ranked by each element's means from highest to lowest. The flight instructors placed more emphasis on flying skills and procedures during their flight training than any other element. Although important to being able to execute a decision safely, it is a reflection of traditional instructional methods. Traditional methods often focus on mastering basic aircraft manipulation, aircraft systems knowledge, and knowledge of aviation regulations with little opportunity to practice ADM skills (Adams, 1994). The overall means of the remaining elements were lower than the faculty means, ranging from 3.65 to 4.6, indicating a lower level of use of ADM elements in general. Instructors were not incorporating these elements consistently in their flight instruction.

Table 5. Instructor Ranking of ADM Elements Used During Flight Training

\begin{tabular}{lccc}
\hline Element & M & SD & Variance \\
\hline 1. Skills and procedures & 4.60 & 0.50 & .25 \\
2. Situational awareness & 4.56 & 0.51 & .26 \\
3. Communication & 4.39 & 0.78 & .61 \\
4. Risk management & 4.36 & 0.64 & .41 \\
5. Change recognition & 4.31 & 0.79 & .62 \\
6. Leadership & 4.30 & 0.63 & .40
\end{tabular}




\begin{tabular}{llll} 
7. Aviation experience & 4.24 & 0.66 & .44 \\
8. Computing time available & 4.17 & 0.89 & .79 \\
9. Course of action analysis & 4.15 & 0.67 & .46 \\
10. Situation assessment & 4.13 & 0.74 & .55 \\
11. Organizational influence & 4.13 & 0.76 & .57 \\
12. Course of action selection & 4.12 & 0.60 & .36 \\
13. Headwork & 4.12 & 0.52 & .27 \\
14. Course of action development & 4.12 & 0.77 & .59 \\
15. Poor judgment chain & 4.09 & 0.67 & .45 \\
16. Attention control & 4.08 & 0.78 & .60 \\
17. Attitude management & 3.96 & 0.72 & .52 \\
18. Dynamic problem solving & 3.96 & 0.77 & .59 \\
19. Values & 3.79 & 0.93 & .87 \\
20. Social influence & 3.78 & 1.04 & 1.09 \\
21. Stress management & 3.67 & 0.96 & .93 \\
22. Personality & 3.65 & 0.71 & .51 \\
\hline
\end{tabular}

\section{Research Question 3: Is there a difference between the ADM elements that should be taught and the ADM elements that are being taught?}

Part II of the professor survey related to which ADM elements faculty members thought instructors should use during flight training, while Part II of the instructor survey sought to identify which ADM elements the instructors were actually using during flight training. Each element was analyzed using an unpaired t-test to determine if there was a significant difference between the means of the faculty responses and the instructor responses. Table 6 presents the statistical analysis of Part II from both surveys with reference to the item number. The degrees of freedom varied based on the number of respondents to each item. The table also lists the ranking placed on each element by each group by their respective means.

There were seven elements that had a p-value of less than .05 at the $95 \%$ confidence interval, indicating a discrepancy between what should be taught and what was actually being taught. The elements that revealed significant differences were: risk management, course of action analysis and selection, situation assessment, headwork, attitude management, and stress management. The level of instruction in these elements needed some improvement with respect to the faculty standards. 
Table 6. Part II Statistical Analysis for the Professor and Instructor Surveys

\begin{tabular}{|c|c|c|c|c|c|c|}
\hline \multirow[b]{2}{*}{ Element } & \multicolumn{2}{|c|}{ Ranking } & \multirow[b]{2}{*}{$\mathrm{t}$} & \multirow[b]{2}{*}{ df } & \multicolumn{2}{|c|}{$95 \%$ CI } \\
\hline & Prof. & Inst. & & & $\mathrm{p}$ & Sig. \\
\hline 16. Risk management & 1 & 4 & 2.67 & 31 & 0.01 & Yes \\
\hline 14. Course of action analysis & 2 & 9 & 3.07 & 30 & 0.01 & Yes \\
\hline 15. Course of action selection & 2 & 11 & 2.61 & 30 & 0.00 & Yes \\
\hline 17. Situational awareness & 2 & 2 & 1.44 & 30 & 0.16 & No \\
\hline 21. Situation assessment & 2 & 10 & 2.49 & 29 & 0.02 & Yes \\
\hline 10. Change recognition & 3 & 5 & 1.27 & 31 & 0.21 & No \\
\hline 12. Headwork & 3 & 11 & 2.69 & 31 & 0.01 & Yes \\
\hline 13. Course of action development & 3 & 11 & 1.91 & 31 & 0.07 & No \\
\hline 11. Attitude management & 4 & 14 & 2.08 & 31 & 0.04 & Yes \\
\hline 18. Skills and procedures & 4 & 1 & 0.14 & 30 & 0.89 & No \\
\hline 20. Stress management & 4 & 17 & 2.36 & 29 & 0.03 & Yes \\
\hline 25. Communication & 4 & 3 & 0.57 & 28 & 0.57 & No \\
\hline 31. Poor judgment chain & 4 & 12 & 1.73 & 28 & 0.09 & No \\
\hline 22. Attention control & 5 & 13 & 1.11 & 29 & 0.27 & No \\
\hline 26. Leadership & 5 & 6 & 0.49 & 28 & 0.63 & No \\
\hline 27. Organizational influence & 5 & 10 & 0.91 & 28 & 0.37 & No \\
\hline 28. Social influence & 5 & 16 & 1.52 & 28 & 0.14 & No \\
\hline 30. Dynamic problem solving & 5 & 14 & 1.50 & 28 & 0.14 & No \\
\hline 24. Computing time available & 6 & 8 & 0.34 & 28 & 0.73 & No \\
\hline 19. Aviation experience & 7 & 7 & 0.38 & 30 & 0.71 & No \\
\hline 23. Values & 8 & 15 & 0.56 & 29 & 0.58 & No \\
\hline 29. Personality & 8 & 18 & 1.04 & 28 & 0.31 & No \\
\hline
\end{tabular}

\section{Research Question 4: Which instructional methods should be used to teach ADM?}

Part I of the professor survey asked respondents which methods of instruction flight instructors should use during flight training. Table 7 lists the ADM instructional methods from most important to least important. The entire faculty agreed that setting a good example for students was a very important training method. Evaluating, correcting, and finding judgment errors were also high on the list. The means of the responses for all methods were between 4.57 and 5.00, indicating that the faculty members were in agreement that all of these instructional methods should be included in flight training. 
Table 7. Professor Ranking of ADM Instructional Methods by Importance

\begin{tabular}{lccc}
\hline Method & M & SD & Variance \\
\hline $\begin{array}{l}\text { 1. Set a good example of Aeronautical Decision Making for their } \\
\text { students. }\end{array}$ & 5.00 & 0.00 & 0.00 \\
$\begin{array}{l}\text { 2. Specifically evaluate students for their ability to exercise good } \\
\text { Aeronautical Decision Making. }\end{array}$ & 4.86 & .38 & .14 \\
$\begin{array}{l}\text { 3. After a lesson, review the poor decisions that were made during the } \\
\text { flight and ways to correct them with their student. }\end{array}$ & 4.86 & .38 & .14 \\
$\begin{array}{l}\text { 4. Encourage students to look for judgment errors during flight. } \\
\text { 5. Place students in situations that encourage them to use good }\end{array}$ & 4.86 & .38 & .14 \\
$\begin{array}{l}\text { Aeronautical Decision Making procedures. } \\
\text { 6. Introduce complex problems with time constraints and stress }\end{array}$ & 4.71 & .49 & .24 \\
$\begin{array}{l}\text { during flight training. } \\
\text { 7. Explain their decision making process during flight so the student } \\
\text { can learn by example. }\end{array}$ & 4.71 & .49 & .24 \\
$\begin{array}{l}\text { 8. Allow students to make go/no go decisions for every flight and } \\
\text { evaluate those decisions. }\end{array}$ & 4.57 & .53 & .24 \\
$\begin{array}{l}\text { 9. Incorporate realistic scenarios into lessons to develop decision } \\
\text { making skills. }\end{array}$ & 4.57 & .53 & .29 \\
\hline
\end{tabular}

\section{Research Question 5: Which instructional methods are being used to teach ADM?}

Part I of the instructor survey asked instructors which ADM instructional method they consistently use during flight instruction. Their responses are ranked from the most frequently used to the least frequently used in Table 8. The ADM instructional methods were somewhat similar in ranking to the Professor sample; however, the level of usage of the elements was low, with means ranging from 3.47 to 4.47 . The instructional method that was used the most by the instructors was setting a good example of decision making for students, similar to the faculty member's high ranking of this method, followed by reviewing poor decisions and ways to correct them, and evaluating students on their ADM skills.

Table 8. Instructor Ranking of ADM Instructional Methods by Level of Usage

\begin{tabular}{lccc}
\hline Method & M & SD & Variance \\
\hline $\begin{array}{l}\text { 1. Set a good example of Aeronautical Decision Making for } \\
\text { students. }\end{array}$ & 4.47 & 0.63 & .40 \\
$\begin{array}{l}\text { 2. After a lesson, review the poor decisions that were made } \\
\text { during the flight and ways to correct them with students. }\end{array}$ & 4.43 & 0.57 & .32 \\
$\begin{array}{l}\text { 3. Specifically evaluate students for their ability to exercise good } \\
\text { Aeronautical Decision Making. }\end{array}$ & 4.4 & 0.67 & .46
\end{tabular}


4. Explain their decision making process during flight so students can learn by example.

5. Place students in situations that encourage them to use good Aeronautical Decision Making procedures.

6. Encourage students to look for judgment errors during flight.

7. Introduce complex problems with time constraints and stress during flight training.

8. Allow students to make go/no go decisions for every flight and evaluate those decisions.

9. Incorporate realistic scenarios into lessons to develop decision making skills. $\begin{array}{lll}4.33 & 0.84 \quad .71\end{array}$

$\begin{array}{lll}4.17 & 0.75 \quad .56\end{array}$

$\begin{array}{lll}3.83 & 0.75 \quad .56\end{array}$

$3.77 \quad 1.01 \quad 1.01$

$3.73 \quad 0.98 \quad .96$

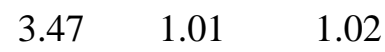

\section{Research Question 6: Is there a difference between the instructional methods that should be used to teach ADM and the instructional methods that are being used to teach ADM?}

After comparing the response means for Part I of the surveys, it was determined that five of the nine instructional methods surveyed revealed a significant difference at the $\mathrm{p}<.05$ level: setting a good example of ADM for students; encouraging students to actively look for ADM errors; introducing complex, time constrained, and stressful problems; allowing students to make go/no go decisions and evaluating those decisions; and the use of realistic scenarios (see Table 9). Interestingly, both the instructors and faculty reported the use of realistic scenarios as least used and least important, respectively. This was the case despite that it has been determined that situational techniques (i.e., scenarios that demanded the use of judgment) were the most effective method to develop decision making skills (FAA, 1991, 2008; Jensen \& Benel, 1977). Pilots need to practice and develop their decision making skills during flight training to compensate for their lack of experience; yet they are not afforded the opportunity to do so. The other areas of instructional methods were close to being in disagreement (p $<.05$ level), indicating that there is an overall disconnect between the methods the faculty members are expecting the instructors to use and the methods the instructors are actually using.

Table 9. Part I Statistical Analysis for the Professor and Instructor Surveys

\begin{tabular}{|c|c|c|c|c|c|}
\hline \multirow[b]{2}{*}{ Item } & \multicolumn{2}{|c|}{ Ranking } & \multirow[b]{2}{*}{$\mathrm{t}$} & \multicolumn{2}{|c|}{$95 \% \mathrm{CI}$} \\
\hline & Prof. & Inst. & & $\mathrm{p}$ & Sig. \\
\hline 8. Set a good example of Aeronautical Decision Making for students. & 1 & 1 & 2.20 & .03 & Yes \\
\hline $\begin{array}{l}\text { 1. Specifically evaluate students for their ability to exercise good } \\
\text { Aeronautical Decision Making. }\end{array}$ & 2 & 3 & 1.74 & .09 & No \\
\hline $\begin{array}{l}\text { 5. After a lesson, review the poor decisions that were made during the } \\
\text { flight and ways to correct them with students. }\end{array}$ & 2 & 2 & 1.89 & .07 & No \\
\hline
\end{tabular}


6. Encourage students to look for judgment errors during flight.

3. Place students in situations that encourage them to use good Aeronautical Decision Making procedures.

4. Introduce complex problems with time constraints and stress during flight training.

7. Explain their decision making process during flight so students can learn by example.

2. Allow students to make go/no go decisions for every flight and evaluate those decisions.

9. Incorporate realistic scenarios into lessons to develop decision making skills.

$\begin{array}{lllll}2 & 6 & 3.50 & .00 & \text { Yes } \\ 3 & 5 & 1.81 & .08 & \text { No } \\ 3 & 7 & 2.38 & .02 & \text { Yes } \\ 3 & 4 & 1.14 & .26 & \text { No } \\ 4 & 8 & 2.18 & .04 & \text { Yes } \\ 4 & 9 & 2.77 & .01 & \text { Yes }\end{array}$

\section{DISCUSSION AND CONCLUSIONS}

Training in judgment and decision making is effective in reducing the number of judgment errors that pilots make (Berlin, et al., 1982; Buch, et al., 1987; Buch \& Diehl, 1984; Connolly \& Blackwell, 1989; Telfer, 1989). Therefore, a flight training program should ensure that its students are receiving ADM training in pertinent areas. This study, like most studies, had some limitations. The population selected, small sample size, and low survey response rate, limit the generalizability of the results. However, these were considered practical limitations and do not necessarily affect the interpretation of the study's findings and conclusions. Another limitation is that since self-reporting was used in this study, it was assumed that the participants were frank and honest in their responses. However, there was the possibility that there were responses perceived to be socially acceptable or that what the instructors reported did not reflect what actually happened during instruction. Part II of the surveys revealed that the professor respondents believed that all elements surveyed were important to the development of ADM skills, and that the instructor respondents were not consistently incorporating the ADM elements. The comparative analysis of the professor and instructor responses from Part II of the survey led to the conclusion that the collegiate program examined had some areas in need of improvement in seven of the 22 elements of ADM. These areas consisted of risk management, course of action analysis, course of action selection, situation assessment, headwork, attitude management, and stress management. It is clear that an intervention is needed to strengthen these areas within the program.

Based on Part I of the professor and instructor surveys, the data indicate that the professor respondents believed that the majority of ADM instructional methods should be used in flight training, and that the instructor respondents were not using the methods of ADM instruction consistently in the aircraft. A comparison of the responses from Part I of the surveys also revealed that five of the nine methods of instruction showed significant differences in how ADM should be taught and how it was actually being taught. The methods of ADM instruction that revealed significant differences were setting a good example of decision making for students; encouraging students to identify judgment errors during flight; introducing complex, time constrained, and stressful problems during flight training; allowing students to make go/no go decisions for every flight; and incorporating realistic training scenarios into lessons. It can be concluded that instructors were not simulating some of the types of in-flight situations that could lead to an error in decision making.

The instructor survey included three items with respect to whether or not the instructor had received 
formal training with respect to how to teach ADM concepts, and where and when the training had occurred. Instructors who had training received it through the university. Several instructors reported that they had not received formal training; it is likely they obtained their CFI licenses outside of the university. Even so, the methods and elements used were similar between the two, concluding that the instructors who had received training were just as likely to omit ADM instruction as those who had not received training. In addition, neither group indicated that their students were provided opportunities to develop their ADM skills.

\section{Implications}

This study has revealed discrepancies between the level and quality of ADM instruction desired and what is being delivered. Accordingly, there are several implications for policy, practice, and research. The FAA and faculty of the university have not provided adequate guidance or enforcement regarding the use of ADM training to its instructors. The professors who participated in the study were all experienced in the field of aviation, and their input can aid in the development of new instructional policy. However, instructors were not implementing the ADM elements and instructional methods they learned during their flight and ground training; instructors should change the way they are teaching ADM in aircraft. Additionally, there has been insufficient research related to the status of ADM instruction. Although the FAA mandates that an applicant for a license must demonstrate good ADM, the training the students have received is not reflecting this mandate. Professors and instructors placed the use of scenarios at the bottom of their lists, which is a strong indication that the efforts of the FAA to encourage scenario-based training have not been entirely successful. In summary, students are not being exposed to the type of training that will allow them to develop into skilled decision makers. If ADM instruction is improved through training, continuous evaluation, and program improvement the possibility of an accident occurring will likely be reduced.

\section{Recommendations}

Several recommendations for policy, practice, and research were derived from this study. First, the FAA should strongly encourage the use of scenario-based training. The FAA has made great progress in recent years with the FITS program, and these efforts should continue. Second, flight training programs should constantly evaluate their flight training to determine if there is a need for improvement of ADM instruction, including student input. This study suggests one method for evaluating ADM training in a collegiate flight school. Once the evaluation is complete, instructor training programs should be developed to address those weak areas in ADM instruction. Students in the program should then be tested on their decision making ability during stage or phase checks to ensure that they are benefiting from the training. Lastly, flight training programs should be revised to include situations that allow the use of ADM. Other flight training programs could use the methods and survey procedures discussed in this study to conduct their own evaluations. It should require minimal additional funding and would benefit students and instructors by identifying weak areas for further development of ADM skills. 


\section{REFERENCES}

Abner, H. L. (2006). The essential elements of aeronautical decision making (Doctoral Dissertation). Available from ProQuest Dissertations and Theses database. (UMI No. 3206689)

Adams, R. J. (1994). Why aren't we teaching aeronautical decision making? Collegiate Aviation Review, $1-8$.

Aircraft Owners and Pilots Association. (2009). 2009 Nall report: Accident trends and factors for 2008. Retrieved from http://www.aopa.org/asf/publications/09nall.pdf

Belanger, B. (2001). The human side of decision-making. FAA Aviation News, 40, 8-12.

Berlin, J. I., Gruber, E. V., Holmes, C. W., Jensen, P. K., Lau, J. R., Mills, J. W., O’Kane, J. M. (1982). Pilot judgment training and evaluation - Volume I. Retrieved from http://www.dtic.mil/cgi-bin/ GetTRDoc?AD=ADA117508\&Location=U2\&doc=GetTRDoc.pdf

Bowman, T. S. (1993). Pilot judgment and decision-making training in post-secondary educational institutions (Doctoral Dissertation). Available from ProQuest Dissertations and Theses database. (UMI No. 9403057)

Brecke, F. H. (1981). Instructional design for aircrew judgment training. In Jensen, R. S. (Ed.), The First Symposium on Aviation Psychology (pp. 145-160). Columbus, OH: Aviation Psychology Laboratory, Ohio State University. Retrieved from http://www.eric.ed.gov/

Buch, G. D., \& Diehl, A. E. (1984). An investigation into the effectiveness of pilot judgment training. Human Factors, 26(5), 557-564.

Buch, G. D., Lawton, R. S., \& Livack, G. S. (1987). Aeronautical decision making for instructor pilots. Springfield, VA: National Technical Information Service.

Cassens, R. E. (2010). Elements Related to Teaching Pilots Aeronautical Decision Making (Master's thesis). Available from ProQuest Dissertations and Theses database. (UMI No. 1479648)

Connolly, T. J., \& Blackwell, B. B. (1989, January). A simulator-based approach to training in aeronautical decision making. Aviation, Space, and Environmental Medicine, 60(1), 50-52.

Diehl, A. E., Hwoschinsky, P. V., Livack, G. S., \& Lawton, R. S. (1987). Aeronautical decision-making for student and private pilots. Springfield, VA: National Technical Information Service.

Federal Aviation Administration. (1991). Aeronautical decision making. Retrieved from http://rgl.faa.gov/Regulatory_and_Guidance_Library/rgAdvisoryCircular.nsf/0/ CCDD54376BFDF5FD862569D100733983?OpenDocument

Federal Aviation Administration. (2003). Pilot's handbook of aeronautical knowledge. Oklahoma City, OK: U.S. Department of Transportation, Federal Aviation Administration, Airman Testing Standards Branch, AFS-630.

Federal Aviation Administration. (2008). Aviation instructor's handbook. Washington, D.C.: Federal Aviation Adminstration. 
Federal Aviation Administration. (2009). FAA FITS information. Retrieved from http://www.faa.gov/training_testing/training/fits/more

Federal Aviation Administration. (n.d.). Personal Minimums Checklist. Retrieved from http://www.faa.gov/training_testing/training/fits/guidance/media/personal\%20minimums\%20che cklist.pdf

Gall, M. D., Gall, J. P., \& Borg, W. R. (2007). Educational research: An introduction (8th ed.). Boston: Pearson Education, Inc.

Jensen, R. S. (1995). Pilot judgment and crew resource management. Brookfield, VT: Avebury Aviation.

Jensen, R. S., \& Benel, R. A. (1977). Judgment evaluation and instruction in civil pilot training (Report No. FAA-RD-78-24). Washington, D.C.: National Technical Information Service.

Joint Safety Analysis Team. (2002). General aviation aeronautical decision making. Retrieved from http://www.faa.gov/safety/programs_initiatives/

pilot_safety/safer_skies/gajsc/gajsc_documents/media/aeronautical.pdf

Kochan, J. A., Jensen, R. S., Chubb, G. P., \& Hunter, D. R. (1997). A new approach to aeronautical decision-making: The expertise method. Retrieved from http://handle.dtic.mil/100.2/ADA323793

Machado, R. (2009, Winter). Experience counts. InstructoReport, 3.

Nunnally, J. C., \& Bernstein, I. H. (1994). Psychometric Theory ( $3^{\text {rd }}$ ed.). New York, NY: McGrawHill, Inc.

Orasanu, J., \& Connolly, T. (1993). The reinvention of decision making. In G. Klein, J. Orasanu, R. Calderwood \& C. Zsambok (Eds.), Decision making in action: Models and methods (pp. 3-20). Norwood, N. J.: Ablex Publishing Corporation.

Orasanu, J., \& Fischer, U. (1997). Finding decisions in natural environments: The view from the cockpit. In C. Zsambok \& G. Klein (Eds.), Naturalistic decision making (pp. 343-357). Hillsdale, N. J.: Lawrence Erlbaum Associates.

Peterson, B. D. (2006). Do the right thing: Decision making for pilots. Retrieved from http://download.aopa.org/epilot/2006/sa24.pdf

Telfer, R. A. (1989). Pilot decision making and judgment. In R. S. Jensen (Ed.), Aviation Psychology (pp. 154-175). Aldershot, England: Gower Technical.

Wright, D. (n.d.). Building a box: A new tool for teaching good judgement. AOPA Flight Training. Retrieved from http://flighttraining.aopa.org/cfi_tools/ publications/inst_reports2.cfm?article $=4901$ 